\title{
Sentinel Lymph Node Mapping
}

National Cancer Institute

\section{Source}

National Cancer Institute. Sentinel Lymph Node Mapping. NCI Thesaurus. Code C20206.

A technique that uses dyes and/or radioactive agents to map the lymphatic drainage of an area in which a tumor is located, thereby identifying the sentinel node. 